\title{
TEMPORAL AND SPATIAL CHANGES OF NUTRIENT CONTENT AND EUTROPHICATION CONDITION IN WATERS OF THE ABANDONED YELLOW RIVER DELTA
}

\author{
ZHANG, Y. M. ${ }^{1}-$ WANG, J. ${ }^{2 *}$ MENG, K. ${ }^{3}-$ ZHAO, L. ${ }^{2}$ \\ ${ }^{1}$ School of Environment, Nanjing Normal University, Nanjing 210023, China \\ ${ }^{2}$ College of Marine Science and Engineering, Nanjing Normal University, Nanjing 210023, China \\ ${ }^{3}$ Jiangsu Yunfan Testing Technology Co., Ltd., Nanjing 210023, China \\ *Corresponding author \\ e-mail: wangjing0108@njnu.edu.cn \\ (Received 28 $8^{\text {th }}$ May 2019; accepted $3^{\text {rd }}$ Sep 2019)
}

\begin{abstract}
This study made use of the trophic state index method, the eutrophication index method, and the potential eutrophication evaluation method to analyze temporal and spatial changes of the nutrient content and the eutrophication level in waters of the Abandoned Yellow River Delta from 2010 to 2015. Findings of this study include the following: the average trophic state index in the study area remained above 3 over the years of investigation, so the study area was under eutrophication; the average eutrophication index each year was above 3 , so the study area was in a medium-eutrophication state; both the average trophic state index and the average eutrophication index showed fluctuating trends and the indices were higher in each autumn than in each spring. Fourth, the study area showed a surplus of nitrogen and deficiency in phosphorus, but the N/P ratio declined from 176.68 to 32.234. The concentration of nutrients and the level of eutrophication declined from the coast to the sea and from north to south, with the estuaries marking the highest concentration and most severe eutrophication. Pollutants discharged from the rivers and development projects along the coastline are the main contributors to the high concentrations of nutrients and eutrophication.
\end{abstract}

Keywords: trophic state index, eutrophication index, potential eutrophication evaluation, distribution, variation, cause

\section{Introduction}

Coastal waters, which connect the continent with the sea, are among the most vibrant areas bustling with human activity and account for some of the world's most important economic belts. The ecology of coastal waters, subject to influence from both the continent and the sea, is susceptible to human interferences and is hence very sensitive and vulnerable. As costal development and ocean exploitation gather pace, and as landsourced pollution exacerbates, the environment of coastal waters deteriorates and nutrients (especially nitrogen and phosphorus) and organic matter increase, which results in eutrophication in the waters (Pinckney et al., 2001; Peru's et al., 2004; Demit et al., 2018). Eutrophication will disturb the ecological balance of the waters, threatens marine ecosystems (Andersen et al., 2006; Cabrita et al., 2015), alters the original ecological system structure (Telesh et al., 1999; Capriulo et al., 2002), and leads to degradation of ecological functions (Diaz et al., 1995; Richardson et al., 1997). Eutrophication has become a major challenge that impedes the sustainable development of coastal areas.

Located in the north-central coast of Jiangsu province in China, the Abandoned Yellow River Delta features an erosion coast and deep waters, having all the ideal 
conditions to build a large port. Additionally, backed by the rich resources of the adjacent continent, the local government plans to build a port with berths able to accommodate 300,000-tonnage vessels along the northern estuary of the Abandoned Yellow River to facilitate industrial transfer from the Yangtze River economic belt and boost the port economy. This area is expected to become a thriving economic engine along Jiangsu's coastline. Nevertheless, as the port develops and industries there take off, the waters of the delta face growing environmental threats. The major environmental problem now confronting the coastal areas of Jiangsu is eutrophication caused by excessive nutrients. Previous studies on eutrophication along coastal areas in Jiangsu focused on Haizhou Bay (Zhao, et al., 2015; Zhang, et al., 2014), but research on eutrophication in waters of the Abandoned Yellow River Delta is still limited. Using the waters of the Abandoned Yellow River Delta as the study area, this study examined water quality data obtained through investigations in 2010, 2012, 2013, and 2015 to analyze trend changes and distribution of nutrients in this area. Using such methods as the trophic state index method, the eutrophication index method, and the potential eutrophication evaluation method, this work probed the causes of pollution in hopes of providing a basis for environmental management and planning, protocols for pollution control, and policies to support environmental protection.

\section{Materials and methods}

\section{Introduction to the study area}

Located in the north-central coast of Jiangsu province in China, the study area stretches from the Zhongshan River estuary to the Northern Irrigation Canal of Jiangsu and extends $20 \mathrm{~km}$ into the sea (as shown in Fig. 1). The study area belongs to the waters of the Abandoned Yellow River Delta. With the headland on the north of the Abandoned Yellow River estuary as the point of inflexion, the coastline which meanders from northwest to southeast then runs from north to south. The coast is a plain erosion silt-muddy coast. The coast is broad and spacious, and the $-15 \mathrm{~m}$ isobath and $10 \mathrm{~m}$ isobath on top of the delta are $3.95 \mathrm{~km}$ and $2.0 \mathrm{~km}$ away from the coastal baseline, respectively, which means the water is deep along the coast and this area offers ideal conditions to build a large port. Currently, a port with berths able to accommodate 100,000-tonnage vessels is under construction in the northern waters of the Abandoned Yellow River Delta. Rivers that join the sea through the study area include Zhongshan River, Fanshen River, the Abandoned Yellow River, and the Northern Irrigation Canal of Jiangsu. The major coastal development activities in the study area include open marine transportation, culture, and discharge of effluent. The port under construction now runs from the Fanshen River estuary to Erhong River estuary. Along the northern seawall of the study area are coastal industrial parks, the industrial effluent from which are discharged into the sea via outfalls $6 \mathrm{~km}$ away from the Zhongshan River estuary and the volume of discharge reaches 20,000 tons per day. The southern part of the industrial park specializes in aquiculture, the wastewater from which is discharged into the sea through the marine outfalls along the coast.

\section{Sampling and sample processing}

Sea water quality investigations were conducted from the waters of the Abandoned Yellow River Delta in May 2010, October 2012, May 2013, and October 2015. In 
October 2010, there were 21 investigation sites in total. In May 2013, October 2012 and October 2015, there were 22 investigation sites. The sampling point coordinate range is $34^{\circ} 10^{\prime} \mathrm{N}-34^{\circ} 30^{\prime} 40.45^{\prime \prime} \mathrm{N}, 120^{\circ} 6^{\prime} \mathrm{E}-120^{\circ} 32^{\prime} 41.33^{\prime \prime} \mathrm{E}$. The areas of investigation remained essentially the same, so data obtained from the investigations have good comparability in terms of space (Fig. 1).

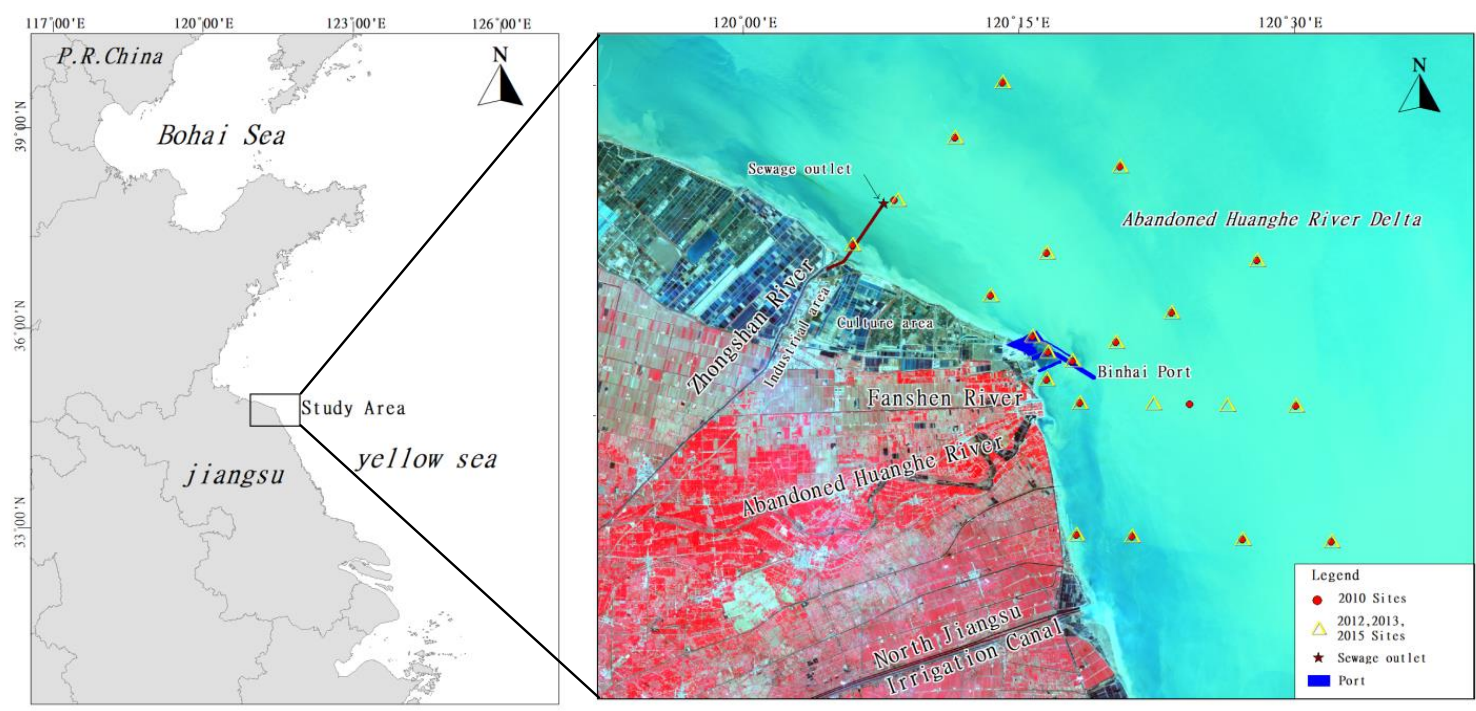

Figure 1. Location of study area and sample sites

Items monitored include chemical oxygen demand (COD), dissolved inorganic nitrogen (DIN, including $\mathrm{NO}_{3}-\mathrm{N}, \mathrm{NO}_{2}-\mathrm{N}, \mathrm{NH}_{4}-\mathrm{N}$ ), dissolved inorganic phosphorus (DIP), chlorophyll a, and salinity. Collection, storage, and transport of samples were performed according to the "Specifications for Marine Monitoring (GB17378-2007)," "Specifications for Oceanographic Survey (GB/T 12763-2007)," and other standards. The water samples were collected from a $50-\mathrm{cm}$ depth where applicable using an Aqua trap water sampler and were then transported to the laboratory for the water quality investigations.

\section{Methods}

\section{Single-factor pollution index method}

The single-factor pollution index method (Jiang et al., 1991) uses the ratio of measured concentration of a given pollutant to the standard concentration to reflect how much pollution the pollutant has caused.

$$
P_{i}=\frac{C_{i}}{L_{i}}
$$

where $P_{i}$ denotes the pollution index of the $i$-th pollutant, $\mathrm{Ci}$ denotes the measured concentration of the $i$-th pollutant, and $L i$ denotes the concentration of the $i$-th pollutant in sea water of standard quality. The evaluation standard used in this study refers to Level-I Standard in "Sea Water Quality Standard (GB3097-1997)". 


\section{Trophic state index (TSI) method}

The trophic state index (TSI) method (Chen et al., 1999; Bian et al., 2013) is one of most widely used methods to assess eutrophication and its calculation equation is as follows:

$$
T S I=\frac{C O D}{C O D_{S}}+\frac{T N}{T N_{S}}+\frac{T P}{T P_{S}}+\frac{\text { Chl.a }}{\text { Chl. } a_{S}}
$$

where COD, TN, TP, and Chl.a stand for the measured concentrations of the pollutants (mg/L), CODs, TNs, and Chl.as their corresponding standard concentrations (mg/L). According to the Level-II standard in the "Sea Water Quality Standard (GB3091-1997)" and the conditions of nutrients in the study area, the standard concentrations for COD, DIN, DIP, and Chl-a are $3 \mathrm{mg} / \mathrm{L}, 0.3 \mathrm{mg} / \mathrm{L}, 0.03 \mathrm{mg} / \mathrm{L}$, and $3 \mathrm{mg} / \mathrm{m}^{3}$, respectively. Table 1 presents the levels of nutrition identified according to the TSI.

Table 1. The levels of nutrition according to the trophic state index (TSI)

\begin{tabular}{c|c}
\hline Trophic state index (TSI) & Level of nutrition \\
\hline Above 3 & Eutrophic \\
$2-3$ & Mesotrophic \\
Below 2 & Oligotrophic \\
\hline
\end{tabular}

\section{Eutrophication index (EI) method}

The eutrophication index (EI) method, first proposed in Japan, was introduced to China by Zou (1983) and has been used according to the "Water Quality Standard for Fisheries" and the "Sea Water Quality Standard" issued by the Chinese government. Its calculation equation is:

$$
E I=\frac{C O D \times D I N \times D I P \times 10^{6}}{4500}
$$

where EI denotes the eutrophication index, and COD (Chemical Oxygen Demand), DIN (dissolved inorganic nitrogen), and DIP (Dissolved Inorganic Phosphorus) refer to the measured concentrations of these pollutants $(\mathrm{mg} / \mathrm{L})$. If $E I<1$, the water is considered as oligotrophic; if $E I \geq 1$, it is considered that eutrophication starts in the water, and the larger $E I$ is, the more severe eutrophication is. If $E I \geq 1$, the water is identified as eutrophic. When $1 \leq E I \leq 3$, the water is identified as slightly eutrophic. When $3<E I \leq 9$, the water is identified as moderately eutrophic. When $E I>9$, the water is identified as severely eutrophic.

\section{Potential eutrophication evaluation method}

When pollution of nutrients occurs in sea water, the The concentration ratio of dissolved inorganic nitrogen and dissolved inorganic phosphorus (N/P ratio) does not equal the Redfield ratio of 16 (Redfield, 1963) and even deviates much from the latter. In such cases, there is a surplus of nitrogen (compared with phosphorus limitation) or phosphorus (compared with nitrogen limitation) and the surplus will not be absorbed by 
marine plants. Excess of nutrients does not make a direct contribution to eutrophication, so it is considered a potential source that may induce eutrophication. In other words, only when a proper amount of phosphorus (compared with phosphorus limitation) or nitrogen (compared with nitrogen limitation) is supplemented do the excess of nutrients play a role in eutrophication (Guo et al., 1998). This is in fact a phenomenon of potential eutrophication. Table 2 displays the division of nutrition levels in potential eutrophication.

Table 2. Division of nutrition levels in potential eutrophication according to N/P ratio

\begin{tabular}{c|c|c|c|c}
\hline Level & Nutrition level & DIN $(\mathbf{m g} / \mathbf{L})$ & $\mathbf{D I P}(\mathbf{m g} / \mathbf{L})$ & $\mathbf{N} / \mathbf{P}$ \\
\hline $\mathrm{I}$ & Oligotrophic & $<0.2$ & $<0.03$ & $8-30$ \\
$\mathrm{II}$ & Mesotrophic & $0.2-0.3$ & $0.03-0.045$ & $8-30$ \\
$\mathrm{III}$ & Eutrophic & $>0.3$ & $>0.045$ & $8-30$ \\
$\mathrm{IV}_{\mathrm{P}}$ & Phosphorus-limited mesotrophic & $0.2-0.3$ & - & $>30$ \\
$\mathrm{~V}_{\mathrm{P}}$ & Medium-phosphorus-limited potential eutrophic & $>0.3$ & - & $30-60$ \\
$\mathrm{VI}_{\mathrm{P}}$ & Phosphorus-limited potential eutrophic & $>0.3$ & - & $>60$ \\
$\mathrm{IV}_{\mathrm{N}}$ & Nitrogen-limited mesotrophic & - & $0.03-0.045$ & $<8$ \\
$\mathrm{~V}_{\mathrm{N}}$ & Medium-nitrogen-limited potential eutrophic & - & $>0.045$ & $4-8$ \\
$\mathrm{VI}_{\mathrm{N}}$ & Nitrogen-limited potential eutrophic & - & $>0.045$ & $<4$ \\
\hline
\end{tabular}

\section{Statistical methods}

The DIN and DIP concentrations in water samples were statistically analyzed by SPSS25, the mean, standard deviation and coefficient of variation were calculated. Combining with the spatial information of station location, the data are processed by using Suffer11 software and Kristin interpolation method, and the spatial distribution maps of DIN, DIP, TSI, EI are drawn.

\section{Results and discussion}

\section{Concentration changes of nutrients and spatial distribution}

The statistical results of dissolved inorganic nitrogen (DIN) and dissolved inorganic phosphorus (DIP) from 2010 to 2015 are shown in Table 3 and Figure 2. The DIN concentration in the delta measured in May 2010 ranged from 0.586 to $1.004 \mathrm{mg} / \mathrm{L}$ in May 2010, with a mean concentration of $0.793 \mathrm{mg} / \mathrm{L}$. In October 2012, the measured DIN concentration ranged from 0.512 to $1.615 \mathrm{mg} / \mathrm{L}$, with a mean concentration of $0.851 \mathrm{mg} / \mathrm{L}$. In May 2013, the measured range of DIN concentrations was from 0.306 to $1.520 \mathrm{mg} / \mathrm{L}$, with a mean concentration of $0.590 \mathrm{mg} / \mathrm{L}$. In November 2015, the DIN concentration ranged from 0.213 to $0.924 \mathrm{mg} / \mathrm{L}$, with a mean concentration of $0.474 \mathrm{mg} / \mathrm{L}$. From 2010 to 2012, the maximum concentration of inorganic nitrogen in the waters of the delta witnessed a considerable increase and the average concentration rose slightly. From 2012 to 2015, both the maximum concentration and average concentration of inorganic nitrogen in this area declined (Fig. 2), and this trend is significant. Data from estuaries (Table 3; Fig. 3) show that the DIN concentration of Zhongshan estuary over the years was obviously higher than the average value of the study area, the DIN concentration of Abandoned Yellow River estuary was slightly higher than the average value in 2010 and 2012, the DIN concentration of Northern Jiangsu Irrigation Canal estuary was slightly higher than the average value in 2010. 
Table 3. Statistical description of dissolved inorganic nitrogen (DIN) and dissolved inorganic phosphorus (DIP) concentrations from 2010 to 2015

\begin{tabular}{|c|c|c|c|c|c|c|}
\hline \multirow{2}{*}{\multicolumn{3}{|c|}{ Item }} & \multicolumn{4}{|c|}{ Time } \\
\hline & & & 2010.5 & 2012.10 & 2013.5 & 2015.11 \\
\hline \multirow{8}{*}{ DIN } & \multirow{5}{*}{$\begin{array}{l}\text { Study } \\
\text { area }\end{array}$} & Maximum concentration $(\mathrm{mg} / \mathrm{L})$ & 1.004 & 1.615 & 1.520 & 0.924 \\
\hline & & Minimum concentration (mg/L) & 0.586 & 0.512 & 0.306 & 0.213 \\
\hline & & Mean concentration $(\mathrm{mg} / \mathrm{L})$ & 0.793 & 0.851 & 0.590 & 0.474 \\
\hline & & Standard deviation & 0.124 & 0.316 & 0.282 & 0.184 \\
\hline & & Coefficient of variation (\%) & $15.6 \%$ & $37.1 \%$ & $47.8 \%$ & $38.9 \%$ \\
\hline & \multicolumn{2}{|c|}{ Zhongshan River estuary } & 1.004 & 1.615 & 1.520 & 0.924 \\
\hline & \multicolumn{2}{|c|}{ Abandoned Yellow River estuary } & 0.943 & 0.856 & 0.450 & 0.451 \\
\hline & \multicolumn{2}{|c|}{ Northern Jiangsu Irrigation Canal estuary } & 0.819 & 0.553 & 0.604 & 0.634 \\
\hline \multirow{8}{*}{ DIP } & \multirow{5}{*}{$\begin{array}{l}\text { Study } \\
\text { area }\end{array}$} & Maximum concentration $(\mathrm{mg} / \mathrm{L})$ & 0.019 & 0.040 & 0.041 & 0.106 \\
\hline & & Minimum concentration (mg/L) & 0.011 & 0.018 & 0.014 & 0.012 \\
\hline & & Mean concentration $(\mathrm{mg} / \mathrm{L})$ & 0.016 & 0.029 & 0.021 & 0.035 \\
\hline & & Standard deviation & 0.002 & 0.006 & 0.007 & 0.018 \\
\hline & & Coefficient of variation (\%) & $14.2 \%$ & $21.9 \%$ & $32.8 \%$ & $51.2 \%$ \\
\hline & \multicolumn{2}{|c|}{ Zhongshan River estuary } & 0.011 & 0.04 & 0.041 & 0.106 \\
\hline & \multirow{2}{*}{\multicolumn{2}{|c|}{$\begin{array}{l}\text { Abandoned Yellow River estuary } \\
\text { Northern Jianosu Irrigation Canal estuarv }\end{array}$}} & 0.019 & 0.027 & 0.016 & 0.036 \\
\hline & & & 0.017 & 0.035 & 0.017 & 0.030 \\
\hline
\end{tabular}

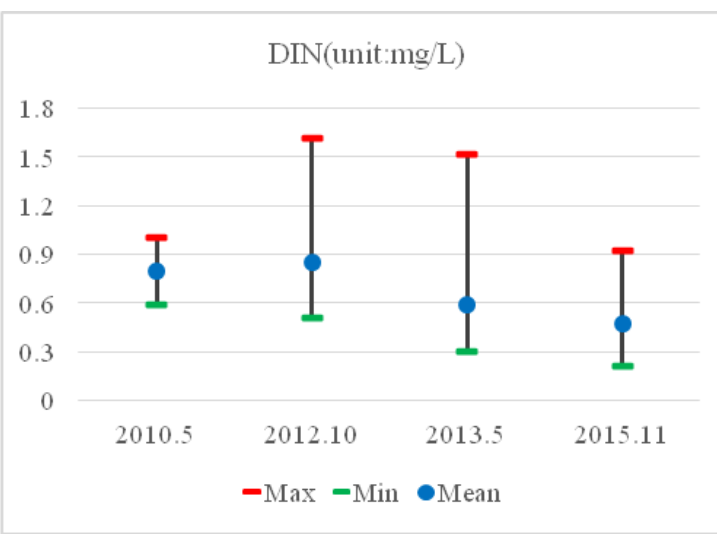

(a) Statistical charts of DIN

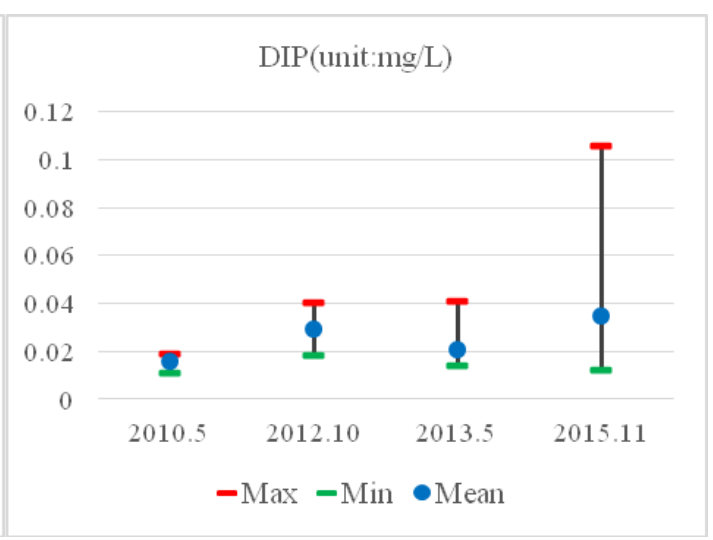

(b) Statistical charts of DIP

Figure 2. Statistical charts of DIN and DIP concentrations from 2010 to 2015

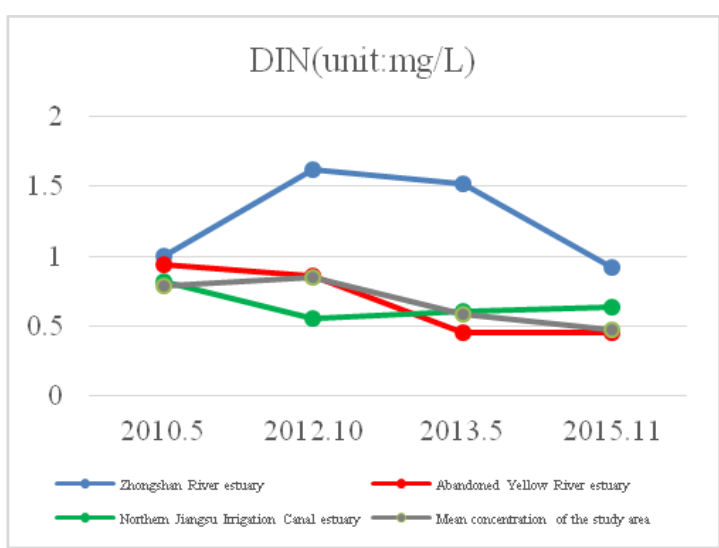

(a) The DIN concentrations of estuaries

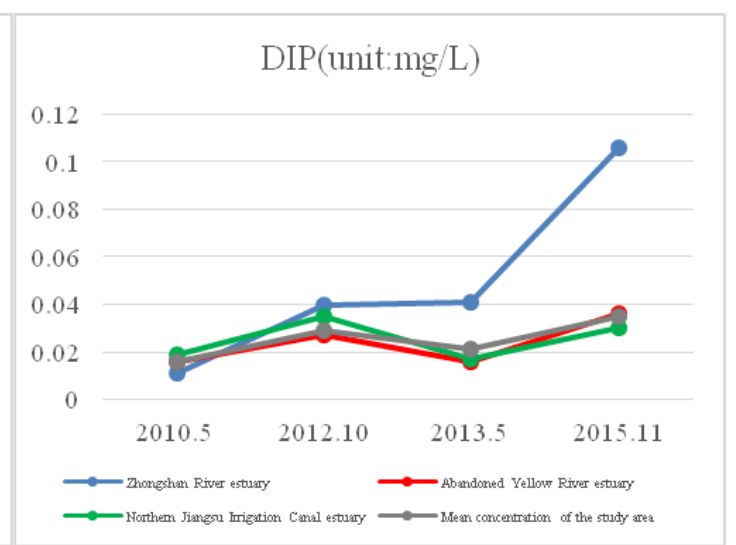

(b) The DIP concentrations of estuaries

Figure 3. The DIN and DIP Concentrations of estuaries from 2010 to 2015 
The DIP concentration in this area ranged from 0.011 to $0.019 \mathrm{mg} / \mathrm{L}$ in May 2010 , with a mean concentration of $0.016 \mathrm{mg} / \mathrm{L}$; the DIP concentration monitored in October 2012 ranged from 0.018 to $0.040 \mathrm{mg} / \mathrm{L}$, with a mean concentration of $0.029 \mathrm{mg} / \mathrm{L}$; in May 2013, the DIP concentration range was from 0.014 to $0.041 \mathrm{mg} / \mathrm{L}$, with a mean concentration of $0.021 \mathrm{mg} / \mathrm{L}$; in November 2015, the DIP concentration range was from 0.012 to $0.106 \mathrm{mg} / \mathrm{L}$, with a mean concentration of $0.035 \mathrm{mg} / \mathrm{L}$. From 2010 to 2015, the maximum concentration of DIP in the study area kept rising (Fig. 2), and this trend is obvious. The average DIP concentration fluctuated, with the concentration higher in autumns than in springs obviously. Data from estuaries (Table 3; Fig. 3) show that the DIP concentration of Zhongshan estuary was obviously higher than the average value in2012, 2013 and 2015, the DIP concentration of Northern Jiangsu Irrigation Canal estuary was slightly higher than the average value in 2010 and 2012, the DIP concentration of Abandoned Yellow River estuary was slightly higher than the average value in 2010 .

The coefficient of variation can reflect the dispersion degree of data distribution at different sampling points. The larger the coefficient of variation, the greater the degree of dispersion. It can also reflect the degree of influence of human factors on water, the larger the coefficient of variation, the greater the influence of human factors. The coefficient of variation of DIN from 2010 to 2015 ranged from 15.6 to $47.8 \%$, with the largest coefficient of variation in 2013. From 2010 to 2015, the coefficient of variation of DIP ranged from 14.2 to $51.2 \%$, and the coefficient of variation increased over the years. This data reflected the uneven spatial distribution of DIN and DIP concentration, which was obviously influenced by human factors.

Regarding spatial distribution (Figs. 4 and 5), the concentrations of DIN and DIP on the surface sea water in the study area declined from the shore outwards and from west to east. It presents a gradient of concentrations in spatial distribution and high concentrations occur near the estuary with the estuary recording the highest. The concentration isolines of DIN in the study area in 2010 are saddle-shaped, with the highest concentrations occurring both at the Zhongshan River estuary and at the Abandoned Yellow River estuary, and the level of pollution in these peak sites was essentially the same. In 2012, the concentration of DIN in these two estuaries remained high, but the concentration at the Zhongshan River estuary far exceeded that at the other estuary. In 2013 and 2015, high DIN concentrations only occurred at the Zhongshan River estuary and the Abandoned Yellow River estuary was no longer a highconcentration area. In 2010 and 2012, the highest concentrations of DIP occurred in areas radiating from the abandoned Yellow River estuary and from the estuary of Northern Irrigation Canal of Jiangsu, but in 2013 and 2015, high DIP concentrations only occurred at the Zhongshan River estuary.

\section{Result of single-factor pollution index evaluation}

Table 4 shows the Single-Factor Pollution Index of dissolved inorganic nitrogen and dissolved inorganic phosphorus (Eq. 1). According to the Level-I standards detailed in "Sea Water Quality Standard," the pollution index of DIN was between 2.931 and 5.021 in 2010, averaging 3.963. In 2012, this index ranged from 2.562 to 8.073, averaging 4.256. In 2013, the index ranged from 1.531 to 7.598, averaging 2.949. In 2015, the index ranged from 1.067 to 4.622, averaging 2.371. The index in all these years exceeded the standard index and, if calculated by the ratio of measured index to the standard, the index first presented an increase and then later a decline. 


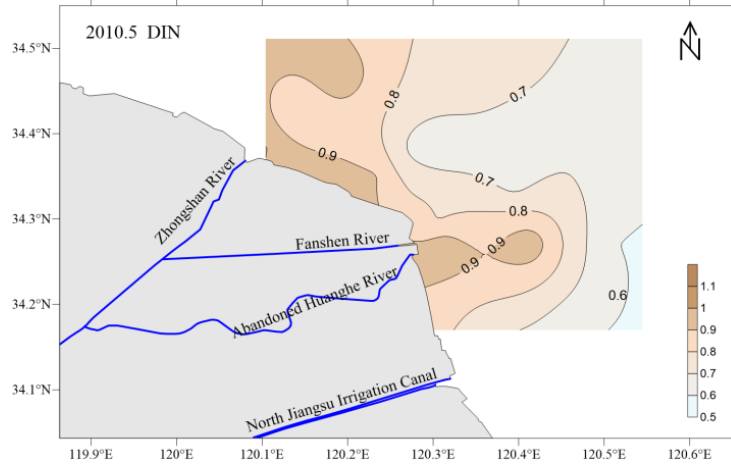

(a) Spatial distribution of DIN in May 2010

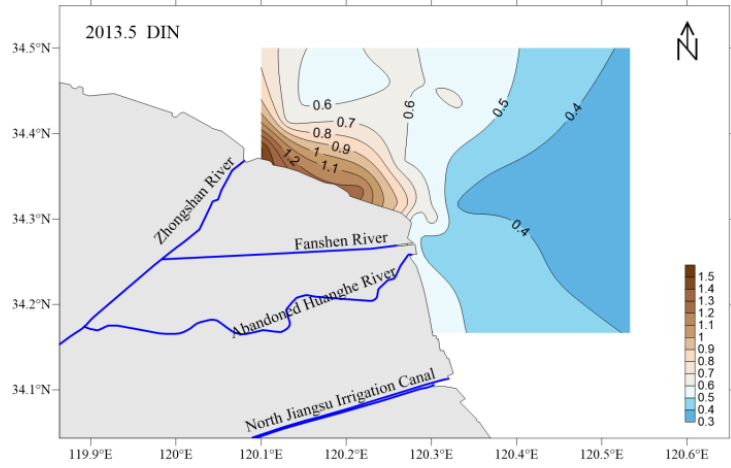

c) Spatial distribution of DIN in May 2013

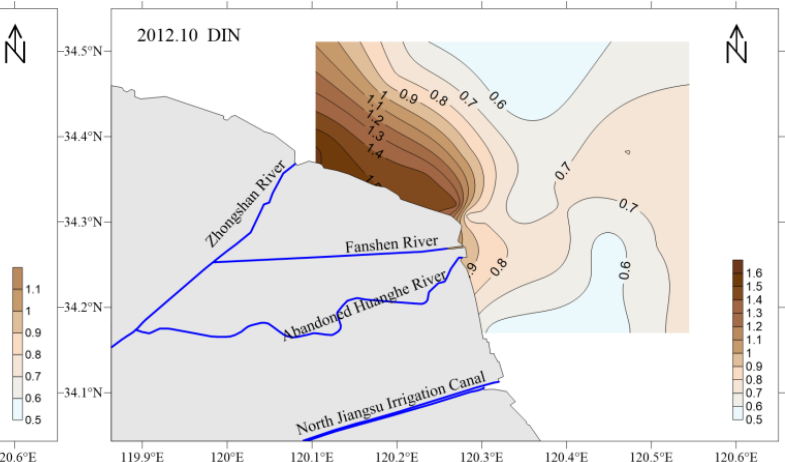

(b) Spatial distribution of DIN in October 2012

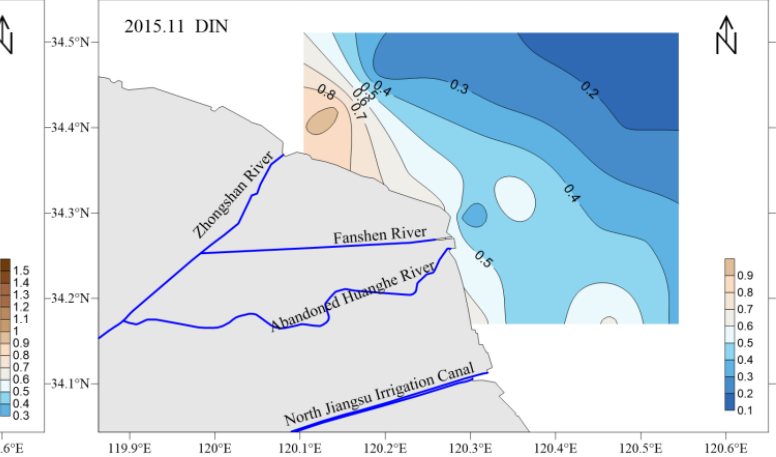

(d) Spatial distribution of DIN in November 2015

Figure 4. Spatial distribution of dissolved inorganic nitrogen (DIN) in the study area from 2010 to 2015 (unit: $\mathrm{mg} / \mathrm{L}$ )

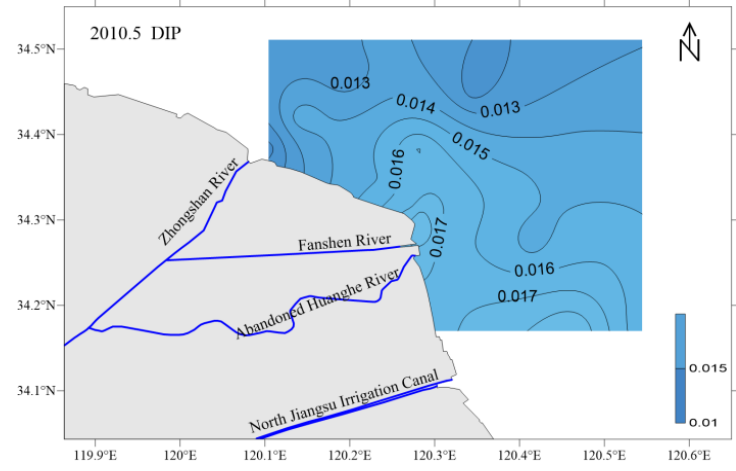

(a) Spatial distribution of DIP in May 2010

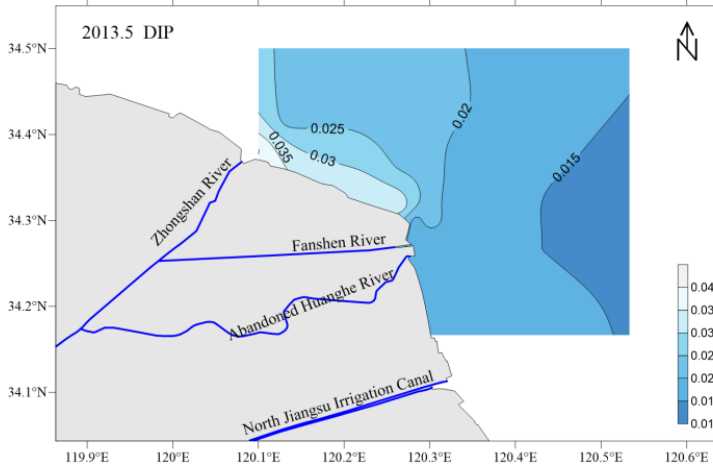

(c) Spatial distribution of DIP in May 2013

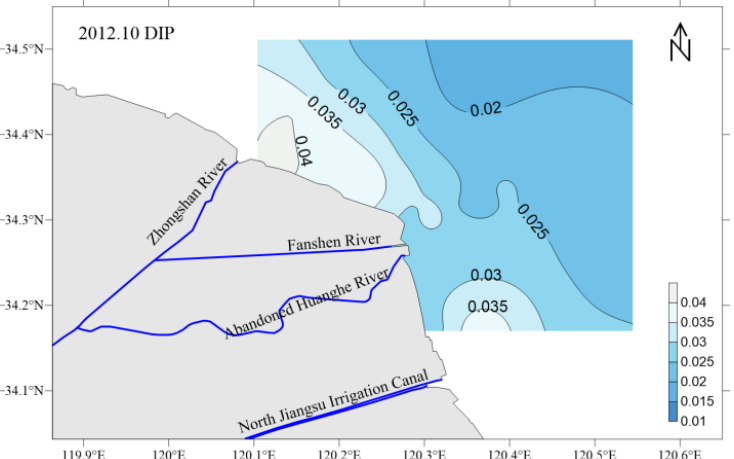

(b) Spatial distribution of DIP in October 2012

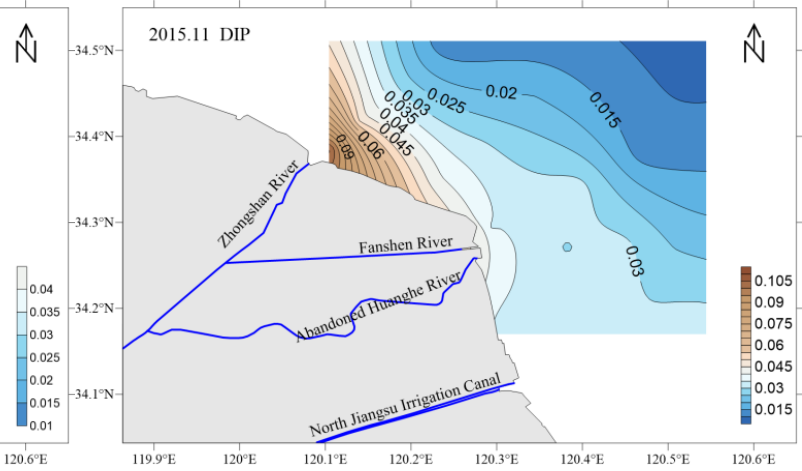

(d) Spatial distribution of DIP in November 2015

Figure 5. Spatial distribution of dissolved inorganic phosphorus $(D I P)$ in the study area from 2010 to 2015 (unit: $\mathrm{mg} / \mathrm{L}$ ) 
Table 4. The single-factor pollution index of dissolved inorganic nitrogen (DIN) and dissolved inorganic phosphorus (DIP)

\begin{tabular}{l|c|c|c|c|c|c}
\hline \multicolumn{2}{c|}{ Item } & \multicolumn{4}{c}{ Time } \\
\cline { 4 - 7 } \multicolumn{2}{l}{ DIN } & & $\mathbf{2 0 1 0 . 5}$ & $\mathbf{2 0 1 2 . 1 0}$ & $\mathbf{2 0 1 3 . 5}$ & $\mathbf{2 0 1 5 . 1 1}$ \\
\hline \multirow{4}{*}{ DIP } & Pollution & Maximum & 5.021 & 8.073 & 7.598 & 4.622 \\
& index & Minimum & 2.931 & 2.562 & 1.531 & 1.067 \\
& & Mean & 3.963 & 4.256 & 2.949 & 2.371 \\
& & Rate of exceeding the standard & $100 \%$ & $100 \%$ & $100 \%$ & $100 \%$ \\
\hline \multirow{3}{*}{} & Pollution & Maximum & 1.267 & 2.687 & 2.687 & 7.067 \\
& index & Minimum & 0.707 & 1.207 & 0.907 & 0.793 \\
& & Mean & 1.037 & 1.909 & 1.370 & 2.310 \\
& Rate of exceeding the standard & $61.9 \%$ & $100 \%$ & $86.3 \%$ & $90.9 \%$ \\
\hline
\end{tabular}

According to the Level-I water quality standards detailed in the "Sea Water Quality Standard," the pollution index (Eq. 1) of DIP in 2010 ranged from 0.707 to 1.267, averaging 1.037, and the rate of exceeding the standard stood at $61.9 \%$. In 2012, the pollution index ranged from 1.207 to 2.687 , averaging 1.909 , and the rate of exceeding the standard was $100 \%$. In 2013, the index ranged from 0.907 to 2.760 , averaging 1.439 , and the rate of exceeding the standard was $87.5 \%$. In 2015, the range of the index was from 0.793 to 7.067 , averaging 2.310 , and the rate of exceeding the standard was $90.9 \%$ (Table 4). The ratio of the measured index to the standard presented a fluctuating pattern, with the value in autumns higher than in springs.

\section{Trophic state analysis}

Table 5 and Figure 6 show the analysis results of the trophic state index (TSI, Eq. 2) in the study area from 2010 to 2015. In May 2010, the TSI of the study area ranged from 3.314 to 5.015 , with a mean index of 4.135 , and the area was identified as eutrophic according to the division standard of nutrition levels. In October 2012, the index changed between 2.864 and 7.509, averaging 4.427, and the area was identified as being between mesotrophic and eutrophic, with an overall tendency towards the eutrophic level. In May 2013, the index ranged from 1.928 to 7.027, averaging 3.227, and the area was identified as being between oligotrophic and eutrophic, with an overall tendency towards the eutrophic level. In November 2015, the index ranged from 2.018 to 7.792 , with the mean standing at 3.974, and the area was identified as being between the mesotrophic state and the eutrophic state, with an overall evaluation as eutrophic. From 2010 to 2015, the TSI value of Zhongshan estuary was significantly higher than the average value of the study sea area and other estuaries values (Fig. 7).

According to the analysis from the angle of time (Table 5), it can be seen that from 2010 to 2015, the average TSI fluctuated but remained above 3 and the area was identified as eutrophic. According to analysis from the angle of spatial distribution (Fig. 8), the TSI of areas near the shore were higher than those far away in the sea and presented a declining trend from the shore to the sea, with high TSIs occurring in waters close to the estuaries. In 2010, the TSI isolines resembled the shape of a saddle; the Zhongshan River estuary and the Abandoned Yellow River estuary had the highest and similar TSIs. In 2012, areas from the Zhongshan River estuary to the shore of the port had the highest TSIs and the index declined outwards from the estuary to the sea. High TSIs also occurred in the Abandoned Yellow River estuary, but the values were generally 
smaller than those in the Zhongshan River estuary. In 2010 and 2012, the researched waters were essentially eutrophic. In 2013 and 2015, the TSI improved compared with 2012 and severe organic pollution only occurred in Zhongshan estuary and the Abandoned Yellow River estuary no longer showed high organic pollution. The area of eutrophic waters shrank and nearly half of the waters were in a mesotrophic state.

\section{Analysis of eutrophication condition}

According to the calculated eutrophication indices of the study area from 2010 and 2015 (as shown in Table 5 and Fig. 9), the eutrophication index (Eq. 3) in this area ranged from 2.114 to 7.798, with a mean index of 4.419 in May 2010, and hence the area was identified as in a state between slight-eutrophic and moderate-eutrophic. In October 2012, the index fluctuated between 2.802 and 29.135, with the mean standing at 8.871 , so the area as identified as being in a state between slight-eutrophic to severeeutrophic. In May 2013, the range of the index was from 0.907 to 23.134, with the mean standing at 4.556 , so the study area was identified as being in a state between oligotrophic to severe eutrophic. In November 2015, the index fluctuated from 0.717 to 29.229 , with the mean standing at 7.252, so the study area was identified as being in a state between oligotrophic and severe eutrophic. From 2012 to 2015, the EI value of Zhongshan estuary was significantly higher than the average value of the study sea area and other estuaries values (Fig. 7).

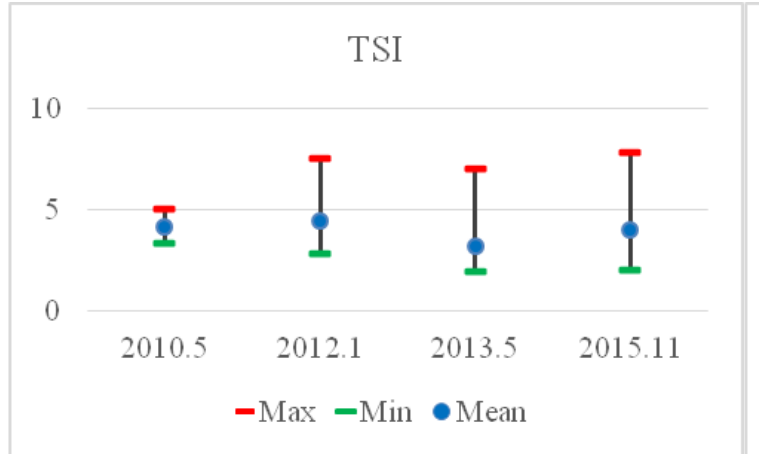

(a) Statistical charts of TSI

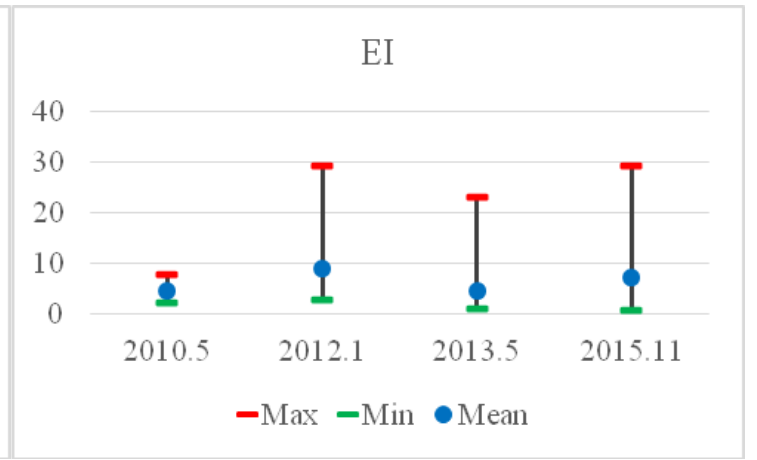

(b) Statistical charts of EI

Figure 6. Statistical charts of TSI and EI from 2010 to 2015 in study area

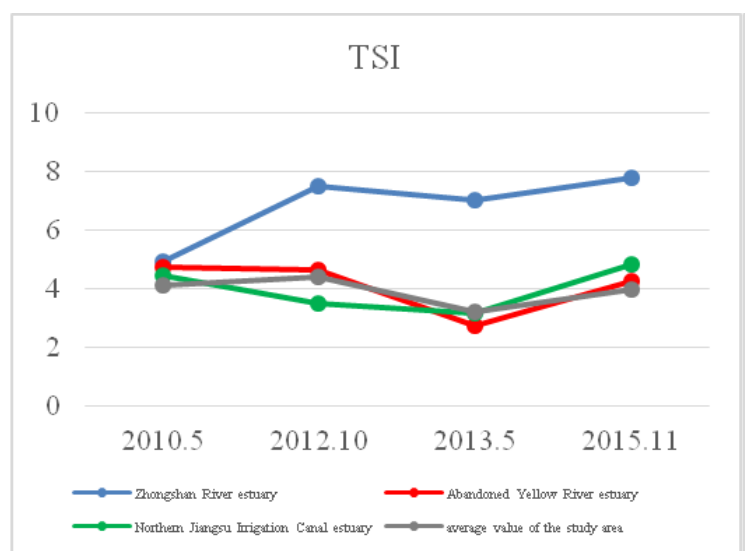

(a) The TSI of estuaries

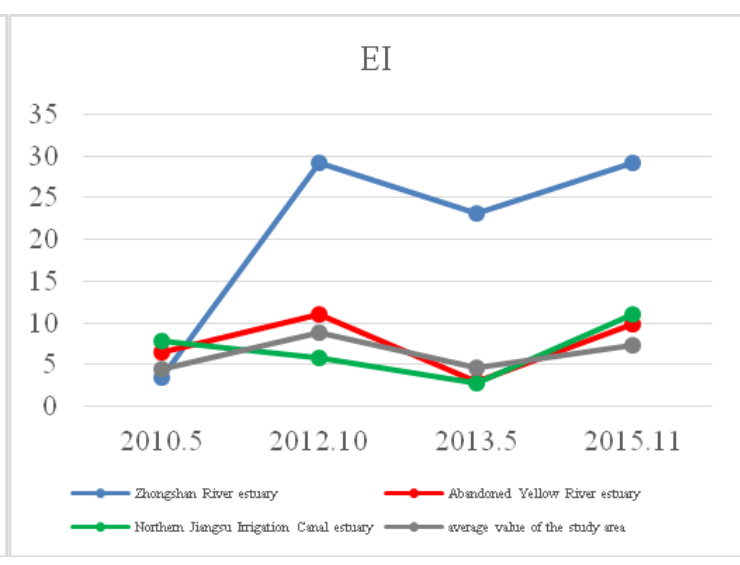

(b) The EI of estuaries

Figure 7. The TSI and EI of estuaries from 2010 to 2015 in study area 


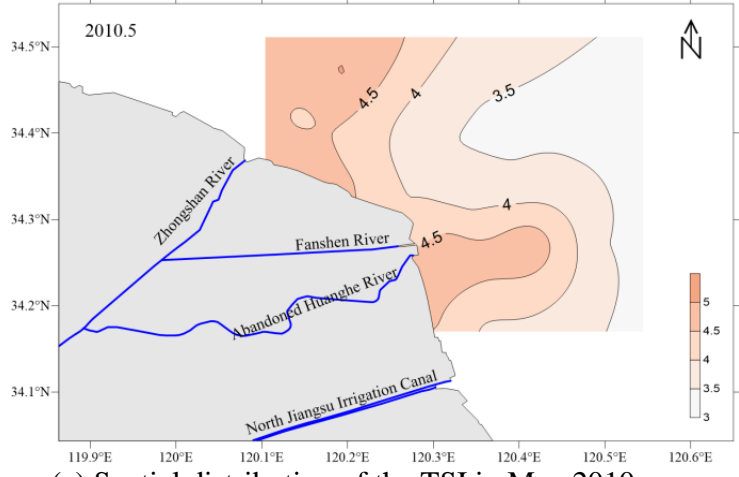

(a) Spatial distribution of the TSI in May 2010

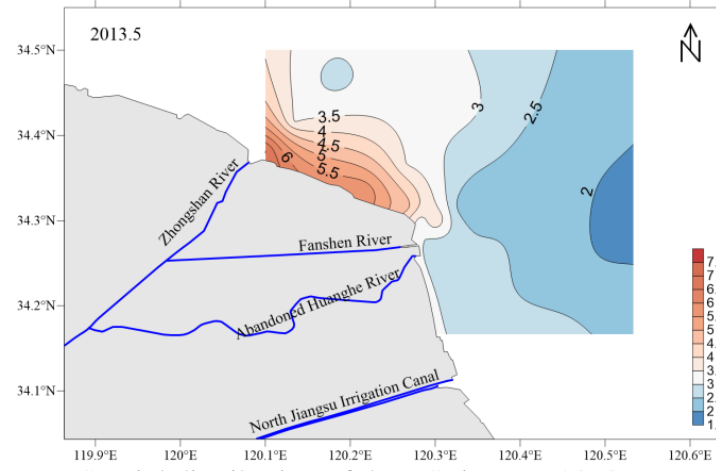

(c) Spatial distribution of the TSI in May 2013

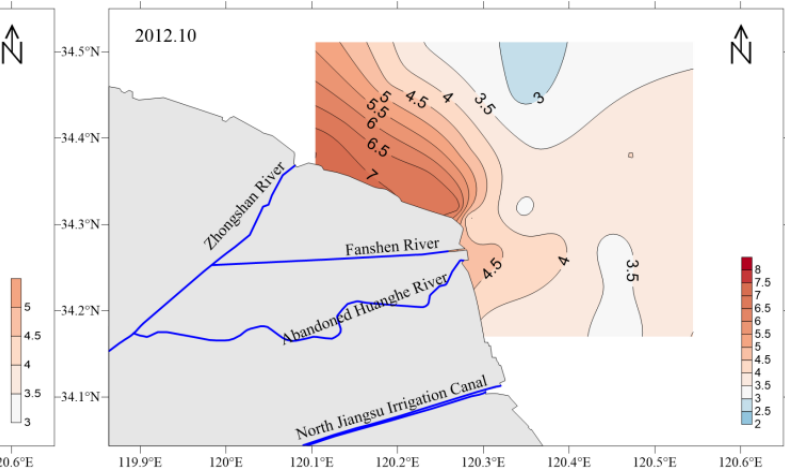

(b) Spatial distribution of the TSI in October 2012

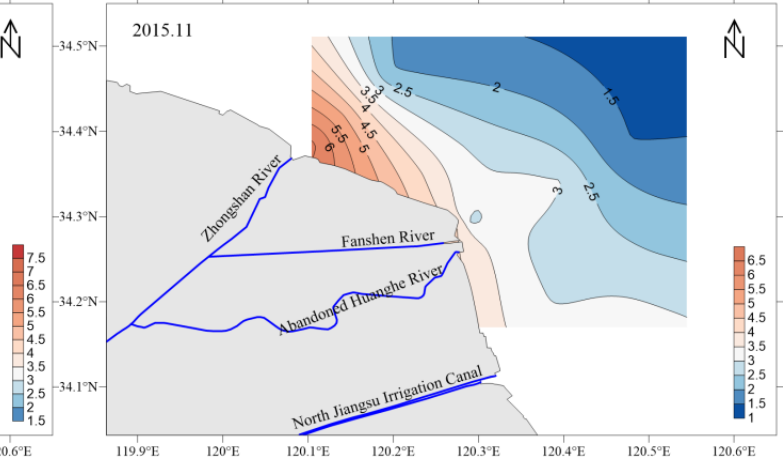

(c) Spatial distribution of the TSI in November 2015

Figure 8. Spatial distribution of the trophic state index (TSI) in the study area from 2010 to 2015

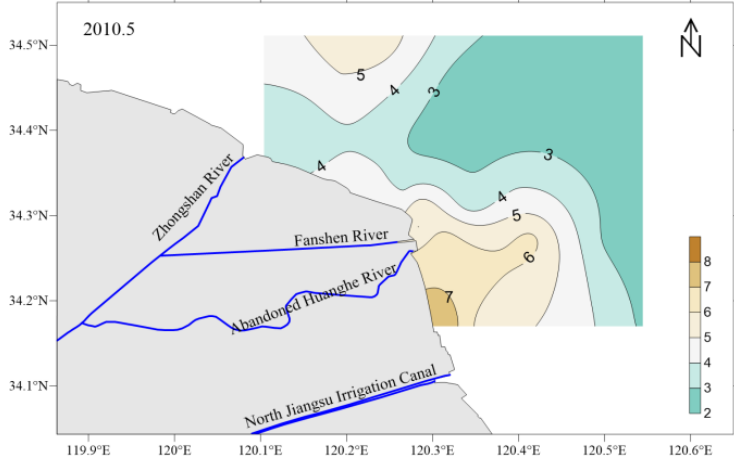

(a) Spatial distribution of EI in May 2010

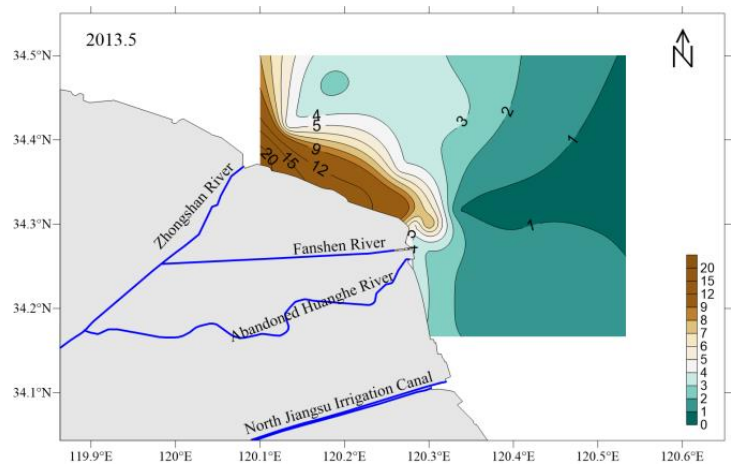

(c) Spatial distribution of EI in May 2013

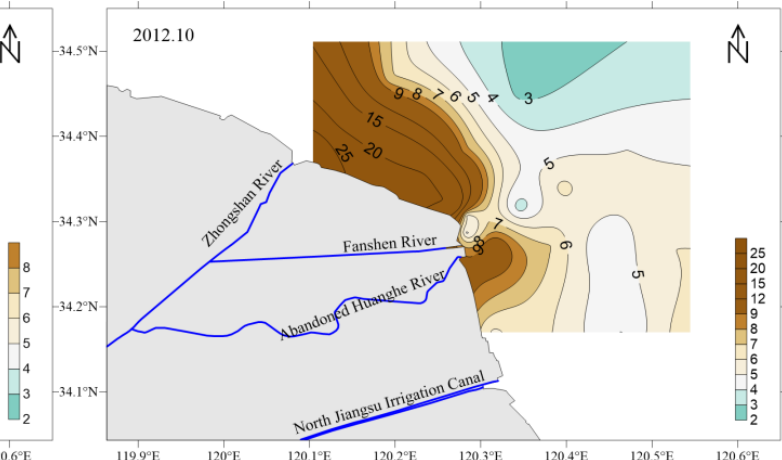

(b) Spatial distribution of EI in October 2012

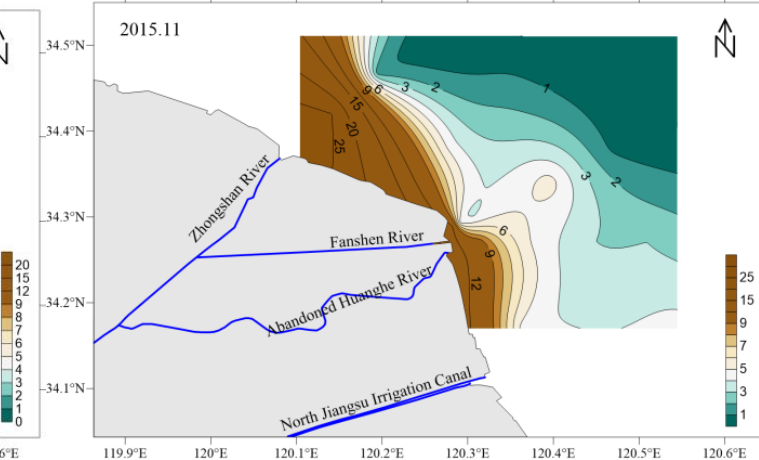

(d) Spatial distribution of EI in November 2015

Figure 9. Spatial distribution of the eutrophication indices (EI) of the study area from 2010 and 2015 
Table 5. Trophic state index (TSI) and eutrophication index (EI) over years

\begin{tabular}{|c|c|c|c|c|c|c|}
\hline \multirow[b]{2}{*}{ Time } & \multirow{2}{*}{\multicolumn{2}{|c|}{ Category }} & \multicolumn{2}{|r|}{ TSI } & \multicolumn{2}{|r|}{ EI } \\
\hline & & & \multirow{2}{*}{$\begin{array}{l}\text { Scale } \\
5.015\end{array}$} & \multirow{2}{*}{$\begin{array}{c}\text { Nutrition level } \\
\text { Eutrophic }\end{array}$} & \multirow{2}{*}{$\begin{array}{l}\text { Scale } \\
7.798\end{array}$} & \multirow{2}{*}{\begin{tabular}{|c|}
$\begin{array}{c}\text { Eutrophication } \\
\text { level }\end{array}$ \\
Moderate-eutrophic
\end{tabular}} \\
\hline \multirow{6}{*}{2010.5} & \multirow{3}{*}{ Study area } & Maximum & & & & \\
\hline & & Minimum & 3.314 & Eutrophic & 2.114 & Slight-eutrophic \\
\hline & & Mean & 4.135 & Eutrophic & 4.419 & Moderate-eutrophic \\
\hline & \multicolumn{2}{|c|}{ Zhongshan River estuary } & 4.954 & Eutrophic & 3.382 & Moderate-eutrophic \\
\hline & \multicolumn{2}{|c|}{ Abandoned Yellow River estuary } & 4.730 & Eutrophic & 6.558 & Moderate-eutrophic \\
\hline & \multicolumn{2}{|c|}{$\begin{array}{l}\text { Northern Jiangsu Irrigation Canal } \\
\text { estuary }\end{array}$} & 4.457 & Eutrophic & 7.798 & Moderate-eutrophic \\
\hline \multirow{6}{*}{2012.10} & \multirow{3}{*}{ Study area } & Maximum & 7.509 & Eutrophic & 29.135 & Severe-eutrophic \\
\hline & & Minimum & 2.864 & Mesotrophic & 2.802 & Slight-eutrophic \\
\hline & & Mean & 4.427 & Eutrophic & 8.871 & Moderate-eutrophic \\
\hline & \multicolumn{2}{|c|}{ Zhongshan River estuary } & 7.509 & Eutrophic & 29.135 & Severe-eutrophic \\
\hline & \multirow{2}{*}{\multicolumn{2}{|c|}{$\begin{array}{l}\text { Abandoned Yellow River estuary } \\
\text { Northern Jiangsu Irrigation Canal } \\
\text { estuary }\end{array}$}} & 4.643 & Eutrophic & 11.063 & Severe-eutrophic \\
\hline & & & 3.514 & Eutrophic & 5.811 & Moderate-eutrophic \\
\hline \multirow{6}{*}{2013.5} & \multirow{3}{*}{ Study area } & Maximum & 7.027 & Eutrophic & 23.134 & Severe-eutrophic \\
\hline & & Minimum & 1.928 & Oligotrophic & 0.907 & Oligotrophic \\
\hline & & Mean & 3.227 & Eutrophic & 4.556 & Moderate-eutrophic \\
\hline & \multicolumn{2}{|c|}{ Zhongshan River estuary } & 7.027 & Eutrophic & 23.134 & Severe-eutrophic \\
\hline & \multirow{2}{*}{\multicolumn{2}{|c|}{$\begin{array}{c}\text { Abandoned Yellow River estuary } \\
\begin{array}{c}\text { Northern Jiangsu Irrigation Canal } \\
\text { estuary }\end{array}\end{array}$}} & 2.733 & Mesotrophic & 2.868 & Slight-eutrophic \\
\hline & & & 3.159 & Eutrophic & 2.791 & Slight-eutrophic \\
\hline \multirow{6}{*}{2015.11} & \multirow{3}{*}{ Study area } & Maximum & 7.792 & Eutrophic & 29.229 & Severe-eutrophic \\
\hline & & Minimum & 2.018 & Mesotrophic & 0.717 & Oligotrophic \\
\hline & & Mean & 3.974 & Eutrophic & 7.252 & Moderate-eutrophic \\
\hline & \multicolumn{2}{|c|}{ Zhongshan River estuary } & 7.792 & Eutrophic & 29.229 & Severe-eutrophic \\
\hline & \multicolumn{2}{|c|}{ Abandoned Yellow River estuary } & 4.253 & Eutrophic & 9.787 & Severe-eutrophic \\
\hline & \multicolumn{2}{|c|}{$\begin{array}{l}\text { Northern Jiangsu Irrigation Canal } \\
\text { estuary }\end{array}$} & 4.855 & Eutrophic & 11.092 & Severe-eutrophic \\
\hline
\end{tabular}

From 2010 to 2015, the mean of the eutrophication index indicated a moderateeutrophic state of the study area, but the highest reading of the index witnessed a significant rise from 2010 to 2012, and the years from 2012 to 2015 marked the largest value of the maximum index, which reflected the fact that part of the researched waters suffered from severe eutrophication. The spatial distribution of the eutrophication index was in alignment with that of the trophic state index.

\section{Potential eutrophication evaluation}

The concentration and makeup of nutrients are of significant importance for the growth of phytoplankton and the N/P ratio is a vital indicator of the makeup of nutrients. When the N/P ratio equals $16: 1$, the waters provide the necessary conditions for the phytoplankton to growth; a smaller ratio will limit the growth of the phytoplankton and a larger ratio will make phosphorus the decisive factor for the phytoplankton's growth. 
According to the observed data regarding concentrations of DIN and DIP from 2010 to 2015 , this study analyzed the potential eutrophication conditions of the study area, as shown in Table 6. In May 2010, the N/P ratio of the study area stayed between 108.818 and 318.031, with the mean standing at 176.680 , so the whole area was in a state of phosphorus-limited potential eutrophication. In October 2012, the N/P ratio of the study area was between 30.654 and 97.282, with the mean standing at 65.433 , and the waters was in a state between medium-phosphorus-limited potential eutrophication and phosphorus-limited potential eutrophication. In May 2013, the N/P ratio was between 45.893 to 83.433 , with the mean standing at 60.639 , so the researched waters were in a state between medium-phosphorus-limited potential eutrophication and phosphoruslimited potential eutrophication. In November 2015, the N/P ratio of the study area was between 18.636 and 54.377, with the mean standing at 32.234, so the study area was in a state of medium-phosphorus-limited potential eutrophication and medium-eutrophication.

Table 6. Result of potential eutrophication evaluation over years

\begin{tabular}{|c|c|c|c|c|c|c|}
\hline Time & Category & $\underset{(\mathrm{mg} / \mathrm{L})}{\mathrm{DIN}}$ & $\begin{array}{c}\text { DIP } \\
(\mathrm{mg} / \mathrm{L})\end{array}$ & $\mathbf{N} / \mathbf{P}$ & Level & Nutrition level \\
\hline \multirow{3}{*}{2010.5} & Maximum & 1.0041 & 0.019 & 318.031 & $\mathrm{VI}_{\mathrm{P}}$ & Phosphorus-limited potential eutrophication \\
\hline & Minimum & 0.5862 & 0.0106 & 108.818 & $\mathrm{VI}_{\mathrm{P}}$ & Phosphorus-limited potential eutrophication \\
\hline & Mean & 0.7926 & 0.0156 & 176.680 & $\mathrm{VI}_{\mathrm{P}}$ & Phosphorus-limited potential eutrophication \\
\hline \multirow{3}{*}{2012.10} & Maximum & 1.6146 & 0.0403 & 97.282 & $\mathrm{VI}_{\mathrm{P}}$ & Phosphorus-limited potential eutrophication \\
\hline & Minimum & 0.5123 & 0.0181 & 30.654 & $\mathrm{~V}_{\mathrm{P}}$ & $\begin{array}{c}\text { Medium- phosphorus-limited potential } \\
\text { eutrophication }\end{array}$ \\
\hline & Mean & 0.8513 & 0.0286 & 65.433 & $\mathrm{VI}_{\mathrm{P}}$ & Phosphorus-limited potential eutrophication \\
\hline \multirow{3}{*}{2013.5} & Maximum & 1.520 & 0.041 & 83.433 & $\mathrm{VI}_{\mathrm{P}}$ & Phosphorus-limited potential eutrophication \\
\hline & Minimum & 0.306 & 0.014 & 49.804 & $\mathrm{~V}_{\mathrm{P}}$ & $\begin{array}{c}\text { Medium- phosphorus-limited potential } \\
\text { eutrophication }\end{array}$ \\
\hline & Mean & 0.602 & 0.022 & 61.712 & $\mathrm{VI}_{\mathrm{P}}$ & Phosphorus-limited potential eutrophication \\
\hline \multirow{3}{*}{2015.11} & Maximum & 0.924 & 0.106 & 54.377 & $\mathrm{~V}_{\mathrm{P}}$ & $\begin{array}{c}\text { Medium- phosphorus-limited potential } \\
\text { eutrophication }\end{array}$ \\
\hline & Minimum & 0.213 & 0.012 & 18.636 & II & Mesotrophic \\
\hline & Mean & 0.474 & 0.035 & 32.234 & $\mathrm{~V}_{\mathrm{P}}$ & $\begin{array}{c}\text { Medium- phosphorus-limited potential } \\
\text { eutrophication }\end{array}$ \\
\hline
\end{tabular}

From 2010 to 2015, the N/P ratio of the researched waters presented a declining trend and the area shifted from phosphorus-limited potential eutrophication to mediumphosphorus-limited potential eutrophication. In the study area, there was excessive nitrogen and deficient phosphorus, but the gap between the content of these two nutrients was narrowing. Once the content of phosphorus rises due to an increased discharge of pollutants from outfalls or rivers, the area will be very likely to suffer from eutrophication.

\section{Analysis of causes}

According to the characteristics of the temporal distribution, the content of nutrients and the eutrophication level in the study area were higher in autumns than in springs, 
which was largely because the phytoplankton begins reproduction and consumes nitrogen and phosphorus in springtime (Li et al., 2018; Sun et al., 2016).

According to the spatial distribution of nutrients and the conditions of eutrophication, the nutrient content declined from the shore to the sea and from north to south, with the estuary marking the highest content. Inside the northern seawall of the study area are coastal industrial parks and aquaculture plants, and outside the seawall are outfalls and berths. Effluents of these human activities discharged into the sea influence the water quality along the northern coastline. As for the southern part of the study area, inside the seawall are farmlands, which produce relatively less pollutants.

The eutrophication level of the study area is largely subject to the pollutants discharged to the sea from the rivers. Industrial effluents, urban sewage, and agricultural wastewater that are rich in such nutrients as nitrogen and phosphorus enter the sea from the Zhongshan River, the Abandoned Yellow River, and the Northern Irrigation Canal of Jiangsu, which increases the content of nutrients in the study area, exacerbates eutrophication, and gives rise to high-content areas that radiate from the estuaries.

The area and condition of high content of nutrients at the estuary vary with the conditions of discharge from the river. Channels of the Zhongshan River, the Abandoned Yellow River, and the Northern Irrigation Canal of Jiangsu are all gatecontrolled channels, so the monitored content of pollutants in the waters near the estuaries was correlated to the status of the gate (i.e. whether the gate was open or not). The salinity of the sea near the estuary during investigations reflected the conditions of discharge of fresh water from the rivers. According to the result of the salinity investigation performed in 2010 (Fig. 10), a low-salinity area occurred in the waters close to the estuaries of these three rivers, which meant that the gates of these three rivers were open at that time. As a result, the estuaries marked the highest content of nutrients and highest level of eutrophication in the study area in 2010. According to the salinity map of 2015 (Fig. 10), waters surrounding the Zhongshan River estuary showed low salinity and waters surrounding the other two estuaries did not, which means the gates of the other two rivers were closed at the time of investigation and thus there was no discharge of freshwater into the sea from these two rivers. Consequently, the high content of nutrients only occurred around the Zhongshan River estuary in 2015. In short, pollutants from the rivers and effluents from production activities along the coastline and the nearby continent are major factors that determine the concentration of nutrients and the level of eutrophication in the study area (Hu et al., 2016; Zhang et al., 2018).

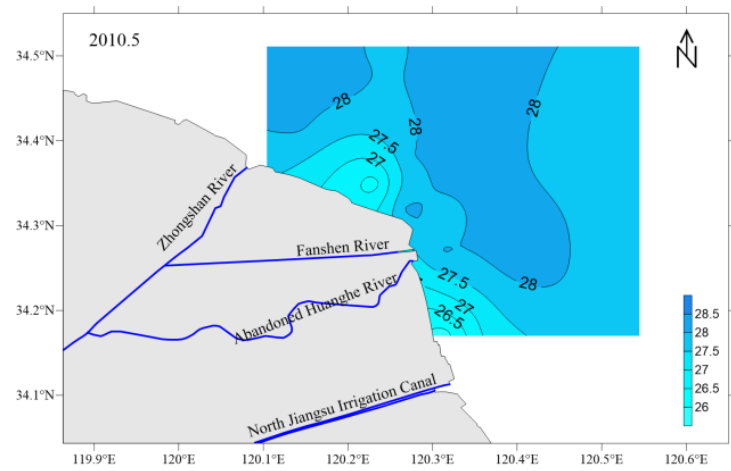

(a) Spatial distribution of salinity in May 2010

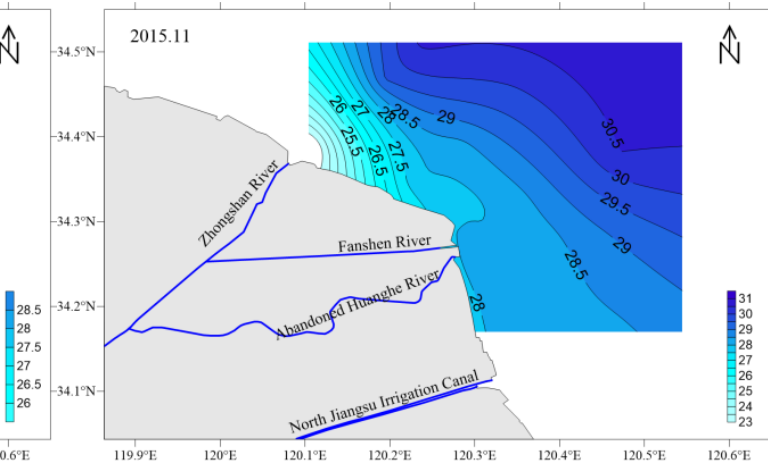

(b) Spatial distribution of salinity in November 2015

Figure 10. Spatial distribution of salinity in the study area in May 2010 and November 2015 (unit: \%o) 
According to the China Marine Environmental Quality Bulletin of 2015, China's marine pollution areas were mainly distributed in Liaodong Bay, Bohai Bay, Laizhou Bay, Jiangsu coast, Yangtze Estuary, Hangzhou Bay, Zhejiang coast, Pearl River Estuary. The main pollution factors were inorganic nitrogen, active phosphate and petroleum. Inorganic nitrogen and active phosphate had become the main pollution factors in China's coastal areas, and the problem of seawater eutrophication was grim. Areas with serious eutrophication were mainly concentrated in estuaries, bays and coastal waters. Land-source pollutants from rivers entering the sea and coastal development activities were the main reasons for eutrophication (Chen et al., 2017; Dai et al., 2016; Li et al., 2018; Sun et al., 2016). Eutrophication had become a water environment problem in coastal waters of China.

Based on four-time water quality data of the Abandoned Yellow River Delta, this study analyzed the trend and distribution characteristics of nutrients in this area. For long-term eutrophication changes, distribution rules and characteristics, continuous monitoring and further analysis of the water quality are still needed in the abandoned Yellow River Delta. For the reasons of eutrophication, this paper makes a preliminary discussion. In the future, quantitative research should be strengthened on the extent and scope of impacts of human activities especially rivers, on eutrophication in coastal waters. In view of the eutrophication problem in coastal areas, it is necessary to reduce the amount of nutrients into the sea from the river and strengthen the regulation of sewage discharge from coastal development activities.

\section{Conclusion}

According to this study, the following conclusions are reached.

First, in 2010, 2012, 2013 and 2015, the average DIN concentration in the study area first increased and then declined, and the average DIP concentration followed a fluctuating trend, with the concentration higher in autumns than in springs. The DIN concentration in all the years of investigation exceeded the standard concentration for Level-I sea water and the rate that the DIP concentration exceeded the standard was between $61.9 \%$ and $100 \%$.

Second, the mean of the trophic state index remained above 3 over the years of investigation and the study area was in a eutrophic state. The mean of TSI fluctuated, with the value higher in autumns than in springs.

Third, the mean of the eutrophication index over the years of investigation indicated that the researched waters were in the medium-eutrophic state; the maximum of the eutrophication index increased from 2010 to 2012, and from 2012 to 2015, it remained relatively high, which means that part of the researched waters were subject to severe eutrophication, with the estuaries marking the most eutrophic areas.

Fourth, there is an excess of nitrogen and a deficiency in phosphorus in the study area, but the N/P ratio declined from 176.680 in 2010 to 32.234 in 2015 , which means the gap between the content of nitrogen and that of phosphorus narrowed and that the researched waters shifted from a state of phosphorus-limited eutrophication to mediumphosphorus-limited eutrophication. If the content of phosphorus rises due to the discharge of pollutants and effluents from rivers, the study area will in all likelihood suffer from eutrophication.

Lastly, according to the analysis from the perspective of time, the content of nutrients and the level of eutrophication in the study area is higher in autumns than in springs, 
which is largely because the phytoplankton begins reproduction and consumes such nutrients as nitrogen and phosphorus during this time. According to the analysis from the perspective of spatial distribution, the content of nutrients and level of eutrophication declines from the land outwards and from north to south, with the estuaries marking the highest values. Pollutants from rivers and effluents from human activities along the coastline and in the adjacent land to the sea are major factors that determine the temporal and spatial distribution of the content of nutrients and level of eutrophication in the waters of the Abandoned Yellow River Delta.

\section{REFERENCES}

[1] Andersen, J. H., Schueter, L., et al. (2006): Coastal eutrophication: recent developments in definitions and implications for monitoring strategies. - Plankton Res 28: 621-628.

[2] Bian, J. Y., Yuan, L., Wang, Q., et al. (2013): Analysis on the trend of seawater quality variation and assessment of eutrophication at Yangshan Deep-water Port. - Marine Science Bulletin 32(1): 107-112.

[3] Cabrita, M. T., Silva, A., et al. (2015): Assessing eutrophication in the portuguese continental exclusive economic zone within the european marine strategy framework directive. - Ecological Indicators 58: 286-299.

[4] Capriulo, G. M., Smith, G., Troy, R., et al. (2002): The planktonic food web structure of a temperate zone estuary and its alteration due to eutrophication. - Hydrobiologia 475/476: 263-333.

[5] Chen, Y. W., Wang, X., Cai, M. H. (1999): Meizhou Bay marine nutrition status evaluation. - Marine Environmental Science 3: 39-42.

[6] Chen, Y., Zhao, Q., Xu, G. P., (2017): Eutrophication assessment of estuary area in the northern part of Liaodong Bay in summer based on artificial neutral network method. Transactions of Oceanology and Limnology 5: 48-57.

[7] Dai, A. Q., Shi, X. Y., Tang, H. J., et al. (2016): The two-grade entropy maximization model for eutrophication fuzzy assessment: a case study of eutrophication assessment in Yangtze River estuary and its adjacent area. - Journal of Ocean University of Qingdao 2016(9): 59-70.

[8] Desmit, X., Thieu, V., Billen, G., et al. (2018): Reducing marine eutrophication may require a paradigmatic change. - Science of the Total Environment 635: 1444-1466.

[9] Diaz, R. J., Rosenberg, R. (1995): Marine benthic hypoxia: A review of its ecological effects and the behavioural responses of benthic macrofauna. - Oceanography and Marine Biology 33: 245-303.

[10] Guo, W. D., Zhang, X. M., Yang, Y. P., et al. (1998): Evaluation of the potential eutrophication of China's offshore waters. - Taiwan Strait 1: 64-70.

[11] Hu, Q., Qu, L., Huang, B. G., et al. (2016): Status and evaluation on nutrients for the adjacent sea water of the Yellow River estuary in autumn of 2014. - Marine Environmental Science 35(5): 732-738.

[12] Jiang, T. L., Xu, H. D., Pan, H. Z., et al. (1991): Present situation and evaluation of water environment in Southwest Laizhou Bay. - Marine Science Bulletin 10(2): 17-52.

[13] Li, P., Guo, Z., Mo, H. L., Wang, D., et al. (2018): Temporal and spatial distribution of guangxi inshore nutrients. - Transactions of Oceanology and Limnology 3: 148-156.

[14] Perus, J., Bonsdorff, E. (2004): Long-term changes in macrozoobenthos in the Åland archipelago, northern Baltic Sea. - Sea Research 52(1): 45-56.

[15] Pinckney, J. L., Paerl, H. W., Tester, P., et al. (2001): The role of nutrient loading and eutrophication in estuarine ecology. - Environmental Health Perspectives 109(5): 699706. 
[16] Redfield, A. C. (1963): The influence of organisms on the composition of sea water. The Sea: 26-77.

[17] Richardson, K. (1997): Harmful or exceptional phytoplankton blooms in the marine ecosystem. - Advances in Marine Biology 31: 301-385.

[18] Sun, W., Tang, X. C., Xu, Y. D., Liu, Y. J., et al. (2016): Characteristics of nutrients and eutrophication assessment of the Laoshan Bay, Qingdao. - Transactions of Oceanology and Limnology 6: 45-52.

[19] Telesh, I. V., Alimov, A. F., Golubkov, S. M., et al. (1999): Response of aquatic communities to anthropogenic stress: a comparative study of Neva Bay and the eastern Gulf of Finland. - Hydrobiologia 393: 95-105.

[20] Zhang, A. Q., Jiang, H. H., Gu, Z. P., et al. (2018): Composition, distribution and seasonal variation of surface seawater nutrients in Jiangsu coastal waters. - Transactions of Oceanology and Limnology 2: 50-59.

[21] Zhang, S., Zhu, Z., Gao, C. M. (2014): The analysis and evaluation of water quality in the artificial reefs areas, Haizhou Bay. - Advanced Materials Research 7: 1368-1375.

[22] Zhao, J. H., Li, F. (2015): The recognition of characteristics and pollution sources of nutrients in Haizhou Bay. - Environmental Science \& Technology 38(12Q): 32-35.

[23] Zou, J. Z., Dong, L. P., Qin, B. P. (1983): A preliminary discussion on eutrophication and red tide in Bohai Bay. - Marine Environmental Science 2(2): 42-53. 